\title{
THE SCHILLING HAEMOGRAM IN OTITIS MEDIA AND MASTOIDITIS OF INFANCY
}

\author{
BY \\ EDWARD C. ROSS COUPER, M.D., F.R.F.P.S., D.P.H. \\ Deputy Medical Superintendent, Alder Hey Children's Hospital, \\ Liverpool
}

In 1938 a survey of the incidence of otitis media and mastoiditis in infancy was published from Alder Hey Children's Hospital (McConkey and Couper, 1938). A clinical classification of such cases was suggested and conclusions were drawn regarding the relative merits of conservative and operative treatment. Simultaneously a second and more detailed investigation was in progress, with certain aspects of which this present communication is concerned.

This second series consists of fifty infants under the age of one year, suffering with an illness characterized by otitis media (sometimes with mastoiditis), and varying degrees of diarrhoea and vomiting. More than half of these children were judged to be suffering from the so-called latent mastoiditis, i.e. they all suffered from otitis media but there were no external signs of involvement of the mastoid process. Four cases, presenting the classical clinical picture of mastoiditis, were also included. The question of diagnosis and treatment is one of great difficulty and importance and briefly resolves itself into two major problems (a) to decide if infection has spread to the mastoid process, and (b) to decide if operation is advisable, and if so, the best time for this treatment.

In an endeavour to find some reliable indication of prognosis, of whether the mastoid antrum was involved or not, and of the optimum time for operation, a series of Schilling counts was performed on each case. There is a great mass of literature on the subject of these counts and their application to all sorts of conditions. For the present purpose it is sufficient to state that the Schilling count is a modification of Arneth's original method of classifying the polymorphonuclear cells into young and old. In the present work additions to the Schilling count elaborated by Crocker and Valentine in 1934 have also been employed.

Schilling in 1911 divided the polymorphonuclear cells into four groups, i.e. segmenters, stabs, juveniles and myelocytes, the segmented cells being regarded as old cells and the others as young forms. The division of the cells into these four groups gives a qualitative analysis of the neutrophilic cells available to combat the infection. The normal adult picture shows no myelocytes, no juveniles, four stabs and sixty-four segmenters, a total of sixty-eight 
neutrophils in each one-hundred white cells ; an increase in the number of young forms, i.e. myelocytes, juveniles and stabs with a decrease in the number of segmenters constitutes the well-known 'left shift,' the degree of 'shift' indicating the severity of the stimulation undergone by the bone marrow. Conversely an increase in the number of segmenters with a fall in the number of young forms indicates a return to normality. If the type of left shift consists only of stabs, it is termed degenerative ; if of stabs, juveniles and a few (four) myelocytes regenerative, if more than five myelocytes appear leukaemoid, and the type of left shift is a measure of the intensity of the intoxication. The Schilling Index is the ratio of combined shift cells to segmenters, i.e. in the normal adult $4: 64$ or $1 / 16$ or 06 . The multiple index (Crocker and Valentine) is the Schilling index multiplied quite arbitrarily by sixteen, giving a normal of one, a simpler number to work with.

The total white count and the ordinary differential count afford information regarding the quantitative strength of the white cells, i.e. the total white count is an estimation of the total number of white cells available in the circulation, and the ordinary differential count gives the percentage of neutrophils in the total white count. In other words these two counts indicate the reproductive power of the bone marrow for producing neutrophilic cells to combat the infection. On the other hand the Schilling count is an estimation of the qualitative strength of the cells in the circulation, i.e. the marrow 'threshold,' a mechanism whereby the maturity of the cells passing into the blood stream is controlled. The marrow threshold is depressed when a large number of immature cells are allowed to escape into the blood stream, producing a shift to the left.

The actual method employed in performing the counts was as follows :-

Heel blood was invariably used because a more satisfactory flow of blood without having to resort to rubbing or pressure may be obtained from this area, and the cases under investigation were cases of otitis media, frequently with discharge, rendering the use of the lobe of the ear inadvisable. The blood was taken off in glass pipettes and immediately conveyed to glass tubes containing the requisite amounts of diluting fluids. Total red counts were not made except in a few cases. The films were spread on ordinary microscopic slides employing a spreader. The spreader consisted of a microscopic slide, two adjacent corners of which had been cut off, giving an edge somewhat narrower than the width of an ordinary slide. Films thus prepared were narrower than the slide bearing them, and the two edges were available for inspection. One series of films was stained with Leishman's stain and another with Wright's stain, but the same stain was employed throughout any one case. The average of two total white counts, made with a Türck ruling, was taken at each estimation. Two hundred cells were counted in each differential count and percentages calculated therefrom, and the neutrophilic cells were then 'Schillingized' by counting an additional two hundred neutrophils. The Schilling index, or ratio of shift cells to segmenters was calculated from the figures so obtained and the multiple index obtained by multiplying the Schilling index by sixteen. Thus in each film the differential count and the Schilling count involved the counting of four hundred cells.

The foregoing remarks apply to the adult blood picture and some consideration of the differences encountered in the infantile blood picture is necessary. According to Schilling there are haematologically three groups: the new-born infant, the nursling and the child from one to six years. The blood picture in the nursling, from which group all the present cases are drawn, remains constant in the first year and up to the middle of the second, 
after which it changes gradually towards the adult picture, attained about the sixth year. The total white count in the nursling group is somewhat higher than in the adult.

The following are figures quoted by Schilling :-

$\begin{array}{llllll}\text { Gundobin } & . & \ldots & \ldots & \ldots & 9000-15,000 \\ \text { Benjamin } & . & \ldots & \ldots & \ldots & 8000-12,000 \\ \text { Romiger } & \text { Welker } & . & \ldots & \ldots & 9200-23,700 \\ \text { Hoffman and Welker } & & . & \ldots & 6200-21,600\end{array}$

Washburn (1934 and 1935) found that the total white count varied from 5000 to 24,000 , the majority being between 8,000 and 16,500 . A high proportion of lymphocytes is characteristic and certain authors describe a slight left shift. Others, notably Ockel (1924) and Schüssler (1924), deny the existence of this slight shift in the normal infant. Ockel stated that 'a left shift in the Arneth sense is not observed in completely normal infants or in the application of the Schilling method,' and Schüssler said 'only exceptionally have I encountered an increase of stab-nuclear forms over 4-6 per cent. without its being possible to find an explanation for it from the condition of the child.' He concluded that the degree of shift is quite independent of age. These authors give their figures and it has been possible to work out the Schilling index as it has been done in the present work. Figures so obtained have been added to the following table of comparative figures, which is quoted from Schilling :-

\begin{tabular}{|c|c|c|c|c|c|c|c|c|c|c|}
\hline ALTHOR & & BAS. & EOS. & MYEL. & JUV. & STABS. & SEG. & LYMPH. & MON. & SCH. I. \\
\hline $\begin{array}{l}\text { Ockel ... } \\
\text { Hoffman and } \\
\text { Welker.. } \\
\text { Schüssler } \\
\text { Romiger .. }\end{array}$ & $\begin{array}{l}\because \\
\cdots\end{array}$ & $\mid \begin{array}{c}0.5-1 \\
0-1 \\
\overline{0-1}\end{array}$ & $\begin{array}{l}1-5 \\
0-7 \\
2 \\
2-4\end{array}$ & $\begin{array}{l}- \\
- \\
-\end{array}$ & $\begin{array}{l}0-1 \\
0-2 \\
0-5\end{array}$ & $\begin{array}{c}0-5 \\
0-9 \cdot 5 \\
2 \\
8\end{array}$ & $\begin{array}{c}15-40 \\
5-49 \\
29 \\
16\end{array}$ & $\begin{array}{c}49-75 \\
42 \cdot 5-90 \cdot 5 \\
61 \\
62-69\end{array}$ & $\begin{array}{c}3-12 \\
0-16 \\
6 \\
6\end{array}$ & $\begin{array}{r}.05 \\
.23 \\
.06 \\
1 \cdot 2\end{array}$ \\
\hline $\begin{array}{l}\text { Adult } \\
\text { Schilling }\end{array}$ & & $0-1$ & $2-4$ & - & $0-1$ & $3-5$ & $51-67$ & $21-35$ & $4-8$ & .08 \\
\hline
\end{tabular}

\section{Schilling haemogram in normal infants}

In view of these conflicting figures a series of twenty normal infants was investigated. These infants were admitted for the operation of circumcision, inguinal hernia, and the like, and were carefully examined for the presence of infection. The average of the figures obtained is as follows :-

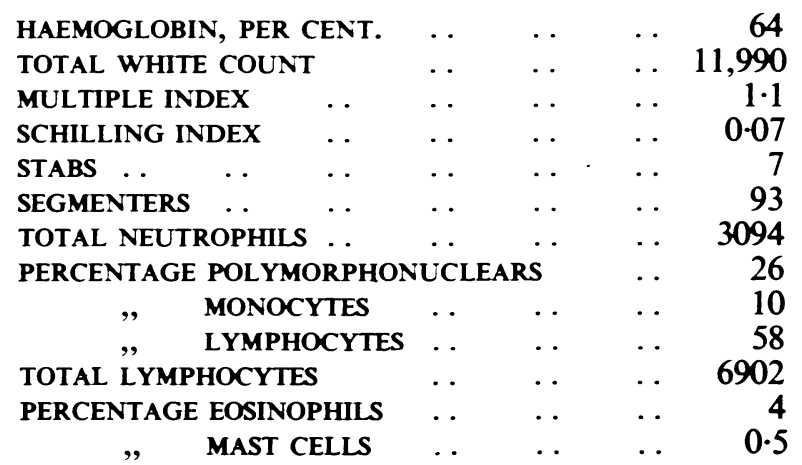


The average total white count and differential count coincide with findings elsewhere, and the results of the Schilling count were found to agree with those who deny a normal left shift, the average Schilling index being 0.07. No juveniles or myelocytes were found. The multiple index throughout has been obtained by multiplying the Schilling index by sixteen. The arbitrary figure sixteen has been used but it will be obvious that it is of no consequence what figure is used provided the same figure is used throughout the series. The only advantage of the multiple index is that it gives more convenient numbers to work with.

Except in the case of the first count, which was taken at whatever hour of the day the child happened to be admitted, the blood for this series was taken between $10 \mathrm{a} . \mathrm{m}$. and $11 \mathrm{a} . \mathrm{m}$., i.e. shortly after the $10 \mathrm{a} . \mathrm{m}$. feed. In view of this it was considered advisable to investigate what effect, if any, feeding had upon the various estimations. A series of counts was therefore taken before and after feeds. The blood was taken half-an-hour before each feed and one hour after the start of each feed, the feed lasting from fifteen to twenty minutes. As each infant was fed at 10 a.m., 2 p.m. and 6 p.m. six counts were obtained throughout the day. Four normal infants were so investigated.

The following is an abbreviated result of one of those investigations, the others being similar.

\begin{tabular}{c|l|c|c}
\hline FEED & TMME & TOTAL WHITE COUNT & MULTIPLE INDEX \\
\hline 10 a.m. & $\begin{array}{l}\text { Before } \\
\text { After }\end{array}$ & 13,900 & .96 \\
& Before & 10,300 & .64 \\
\hline 2 p.m. & $\begin{array}{c}9400 \\
\text { After }\end{array}$ & 10,600 & $\cdot 80$ \\
& Before & 12,700 & $1 \cdot 1$ \\
\hline 6 p.m. & After & 9500 & $1 \cdot 1$ \\
& & & $1 \cdot 2$ \\
\hline
\end{tabular}

It will be seen that feeding appears to exert no systematic effect on these estimations. In 1900 Japha conducted experiments on fourteen healthy infants, i.e. infants who had recovered from a variety of illnesses, and came to the conclusion that "in the infant digestive leucocytosis cannot be regarded as a phenomenon occurring with any regularity.' A similar finding was recorded among sick children. Mitchell in 1915 came to the conclusion that bottle-fed babies do not constantly show digestive leucocytosis. Sabin et al. (1925) made no mention of infants. In 1927 Fletcher and Mitchell said that there are marked daily variations but "any variation in the leucocyte count, which can be interpreted as a digestive leucocytosis, is inconstant.' Washburn (1934), stated that "there is no demonstrable correlation between the variations in the number of white cells and such factors as intake of food, digestion, sleep, increased activity or minor external disturbance.'

Rogatz (1930) commented favourably on the use of the Schilling count in a series of cases, the majority of which were under one year. In 1934 Klenerman found much higher proportions of 'band' forms in infantile bloods and went so far as to state that very few polymorphs show true segmentation. Martin and Ellenberg (1935) confirmed the usefumess of the Schilling count in children, but Washburn (1935) thought the method too time-consuming. 
Schilling haemogram in aural infection

There is little to be found in the literature regarding the effects of aural infection on the blood picture especially in infancy, and a large proportion of the work done deals with older children and adults.

The earliest available work applying haematology to otology was by Darling (1908). He concluded, from work done on patients of all ages, that the number of leucocytes per c.mm. was an indication of the body reaction to infection,' and he found that repeated examination was of greater value than a single estimation. Also in 1908 Dench came to the conclusion that the differential count was of no value as an aid to diagnosis. Gale in 1928 found left shift and an index calculated therefrom unreliable in making a diagnosis in otological complication, e.g. perisinus abscess, and of no help in determining when to operate. In 1931 Rosenwasser and Rosenthal found total white counts and ordinary differential counts inadequate and the Schilling count of great value as a diagnostic aid in otitic infections. Applied to ear infections Weiss (1931) found that 'staff' counts were useless as a diagnostic aid or as an indication for operation, because cases of acute otitis media often showed higher 'staff' counts than cases of mastoiditis, but when used in a series they are of ' inestimable importance in prognosis.' Boies (1931) reported similar findings. Alden and Demotte (1931) who are in agreement regarding the usefulness of the 'staff' count, stated that it 'offers a much more reliable index of the patient's condition than does the polymorphonuclear percentage of the total white count and particularly in children, than the pulse and temperature variations.' No work has been found on the application of these counts to otitis media and the so-called latent mastoiditis of infancy.

It would be impossible in the space available to describe fully the fifty cases examined by this method. Therefore seven illustrative cases have been selected and the following is a detailed description of these cases. Each case consists of (1) a short clinical summary giving dates of admission, discharge, age, sex, result, history, condition on examination, progress while in hospital and results of investigations and post-mortem examination, if any, and (2) a graph with description, plotting the infant's weight, total white count, total polymorphonuclear count and multiple index, and showing dates upon which myringotomies or posterior drainage were performed. At the bottom of each graph a simple line indicates the dates during which the infant's ear or ears were discharging and below this line a block graph indicates the number of stools passed per diem.

\section{Case 1.}

\section{Case reports}

M. M., female, aged $9 \frac{1}{2}$ months, was admitted on 26.9 .36 and discharged on 4.1.37.

History. There was a history of two loose, green stools on the evening before admission. The infant had been taking its feeds well.

CONDITION ON EXAMINATION was fair with no dehydration. The right tympanic membrane was injected and bulging, but other examination negative. Temperature was $99^{\circ} \mathrm{F}$.

Progress. Right myringotomy was performed but no pus obtained. Condition improved until 12.10 .36 when temperature rose to $99^{\circ} \mathrm{F}$., and weight- 
loss began. Both tympanic membranes were very injected, the right bulging slightly posteriorly. On 14.10.36 left tympanic membrane was bulging, left myringotomy was performed, and pus released. On 17.10 .36 further weightloss occurred and the right tympanic membrane was still very red and bulging somewhat. Right myringotomy was performed but no pus obtained. On 21.10.36 the infant lost $14 \mathrm{oz}$. in weight. Bilateral posterior drainage was performed : on the left side the bone was hyperaemic while there was pus on the right side with rather soft bone. On 29.10 .36 both wounds were satis-

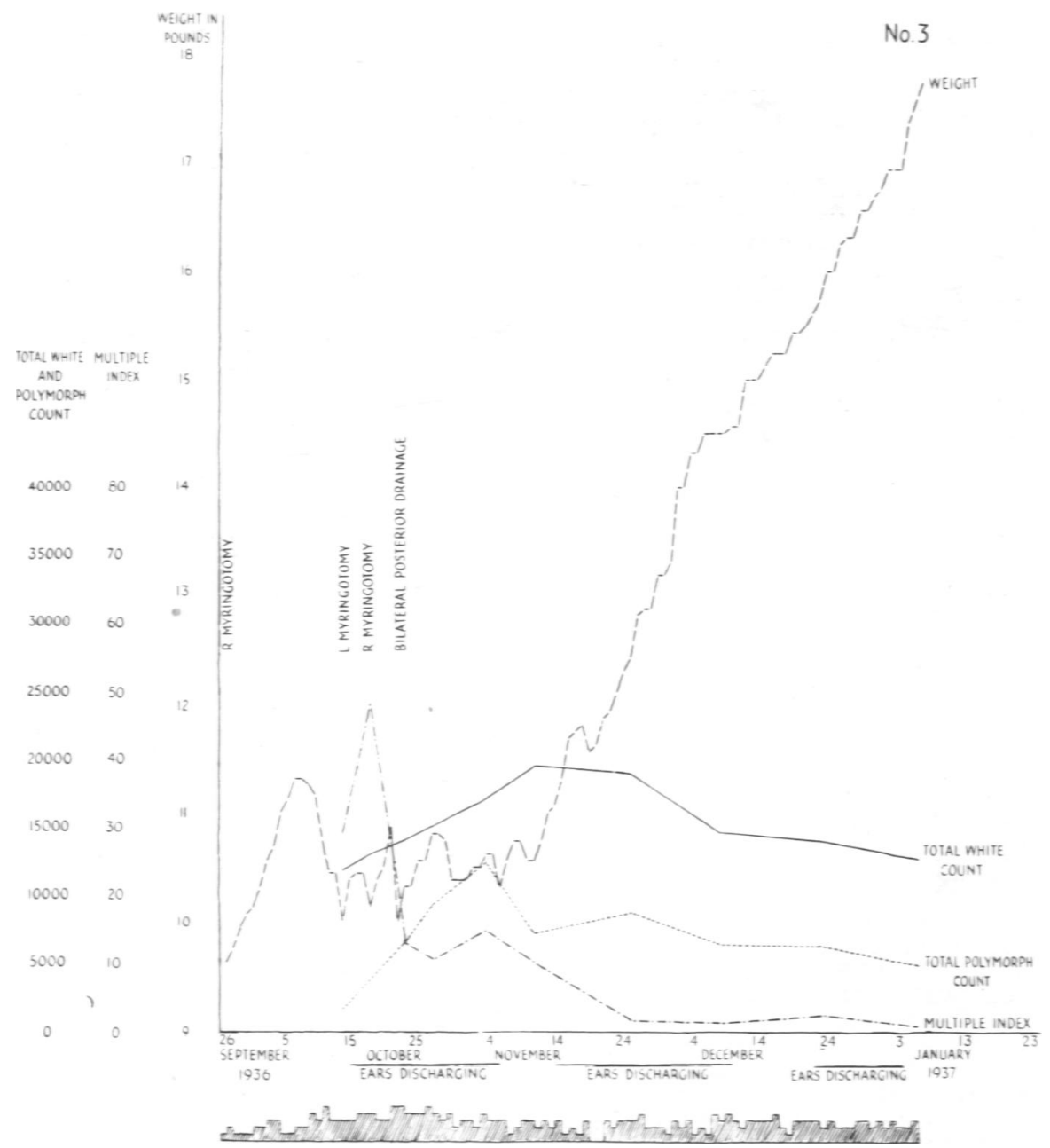

Fig. 1.-Investigations on this case were unfortunately not begun until the child had been in hospital for some time. The multiple index was high at first estimation and rose sharply. It then fell considerably and was actually falling at time of operation. Decision to operate was made on account of the heavy weight loss which occurred on 21.10.36 and the child's poor general condition; it was becoming toxic. The fact that multiple index was falling at time of operation and, although it remained elevated, it was a lower figure, suggests that possibly the infant might have recovered without operation. It will be noticed that the beginning of the fall of multiple index to normal coincides with the start of the infant's final gain in weight, i.e. the two curves diverge. The total white count was never markedly elevated and was rather on the low side in the more acute stage of the illness. There was good neutrophilic response following operation. 
factory and there was still slight discharge from the left meatus. On 3.11.36 temperature rose to $103^{\circ} \mathrm{F}$. and stools were loose. Both wounds looked satisfactory, the right being almost healed. There was slight discharge from the right ear. On 9.11.36 the child was apyrexial but weight was stationary. On 23.11.36 the infant was gaining weight steadily, both wounds were healed, but there was still slight left otorrhoea. Condition continued satisfactory until discharge from hospital on 5.1.37.

INVESTIGATIONS.

Swabs : Nose-Staph. aureus.

Throat-Staph. and diphtheroids.

Right ear-Staph. albus.

Left Ear-Staph. and pneumococci.

Operative swabs : sterile.

Urine : faint trace of albumin, occasional red cells.

Faeces : no pathological organisms.

Blood culture : negative.

Mantoux reaction : negative.

Case 2.

W. S., male, aged 2 months, was admitted on 4.10 .36 and discharged on 20.1.37.

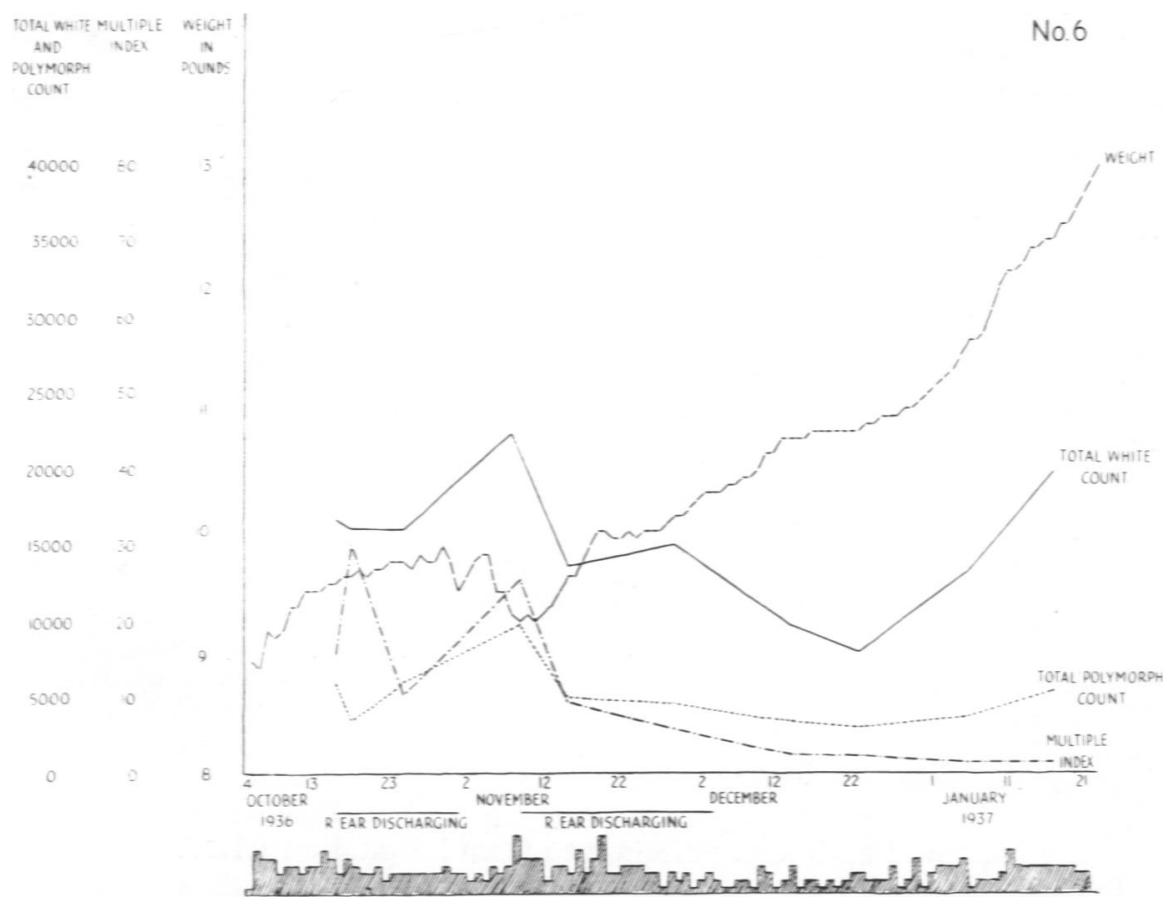

Fig. 2.- The multiple index was raised at the teginning and remained so throughout the period when gain in weight was unsatisfactory. It fell and rose again as otorrhoea ceased and weight fell. It fell again on 14.11.36 and continued to do so until it became normal and from that date weight began to go up-the two curves diverged. The total white count was not high to begin with when the multiple index was a more accurate guide, and its rise preceded the rise of total white count on 8.11.36. The total white count was actually rising when the child was discharged but the multiple index was normal and it was considered safe to discharge the infant. Throughout, the multiple index reflected the clinical condition of the child much more accurately than the total white count or total polymorphonuclear count. 
History. This child had refused feeds for one week and vomited for three days. He was not unduly fretful, but stools were loose and there was some loss of weight.

CONDITION ON EXAMINATION. Left tympanic membrane was red but otherwise examination was negative. Temperature was $99^{\circ} \mathrm{F}$. and stools very loose and frequent.

Progress. Temperature subsided but stools continued loose and child did not gain weight satisfactorily. On 15.10.36 there was copious right otorrhoea with an injected tympanic membrane. Left tympanic membrane was slightly injected but there was no bulging. On 28.10.36 general condition was better, the stools had improved, but gain in weight was unsatisfactory. Right tympanic membrane was slightly injected but there was no discharge. On 4.11.36 weight loss began and temperature rose to $99^{\circ} \mathrm{F}$. and on 7.11.36 right ear was again discharging profusely. Discharge continued for some time and weight gain continued. On 21.12.36 tympanic membranes were lustreless with no discharge and general condition was much improved. General condition then improved until discharge from hospital on 20.1.37.

INVESTIGATIONS.

Swabs : Nose and throat-Staph., pneumococci and M. catarrhalis. Right ear-pneumococci.

Urine : faint trace of albumin.

Faeces : B. Morgan I.

Blood culture : negative.

Mantoux reaction : negative.

Case 3. 1.1.37.

B. N., male, aged $4 \frac{1}{2}$ months, was admitted on 6.11.36, and discharged on

History. This child had a history of screaming and putting its hand to its right ear, vomiting, not gaining weight satisfactorily, loose stools and restlessness.

CONDITION ON EXAMINATION. Left and right tympanic membranes were full and red posteriorly. Other examination was negative and the temperature was not elevated.

Progress. A few days later child was gaining weight with temperature still normal. The left tympanic membrane was red and bulging and there was profuse discharge. The right tympanic membrane was red. On 20.11.36 weight-loss began and on 24.11 .36 temperature rose to $99.8^{\circ} \mathrm{F}$., the child looked ill and toxic, and passed loose stools. The left tympanic membrane was reddened posteriorly with slight bulging. Myringotomy was performed but no pus obtained. On 29.11.36 there was slight discharge from the left ear and pyrexia was still present. On 30.11.36 left myringotomy was repeated and a small quantity of thick pus obtained. On 3.12 .36 temperature was $100 \cdot 8^{\circ} \mathrm{F}$. and the left ear was discharging and meanwhile weight had been unsatisfactory. By 11.12.36 general condition was much better, the tympanic membranes were just slightly pink and there was no discharge. The child's condition then gradually improved until it was discharged from hospital on 1.1.37.

INVESTIGATIONS.

Swabs : Nose-Staph. and diphtheroids.

Throat-Staph. alb., M. catarrhalis and pneumococci.

Right ear - : Staph. albus.

Urine : faint trace of albumin.

Faeces : B. Morgan I \& V.

Blood culture : negative.

Mantoux reaction : negative. 


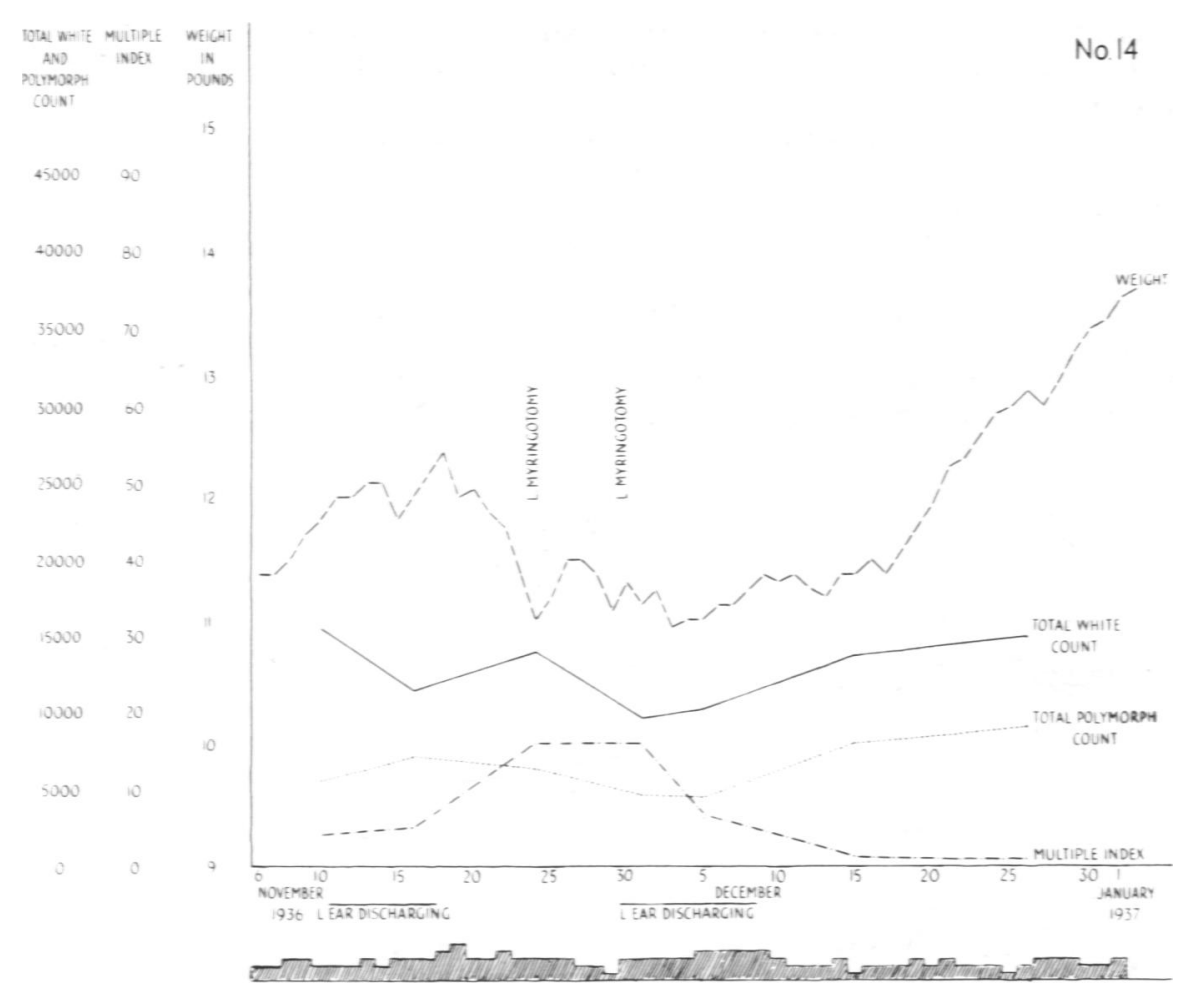

Fig. 3.-The multiple index was raised to begin with and rose still further when otorrhoea ceased. This rise coincided with a marked weight loss when the child was very ill. After drainage had been re-established the multiple index fell and at that point weight began to go up. The weight curves and multiple index curve converge during the ill period and diverge as the child recovered. The total white count was never outside normal limits, i.e. the multiple index was a much more accurate guide as to the infant's condition.

\section{Case 4.} 8.1.37.

B. B., male, aged 8 months, was admitted on 21.11.36, and discharged on

History. This child had had a 'cold' four days previously. He was drowsy and would not take his feeds. Vomiting occurred but no diarrhoea. Temperature was $103^{\circ} \mathrm{F}$.

Condition on examination. He was a large, well-nourished boy. Throat was slightly injected and there were a few moist sounds at both bases. The tympanic membranes seemed normal.

Progress. On the following day there was some nasal discharge, but otherwise his condition was unchanged. On the 22.11.36 the left tympanic membrane was red and bulging and the right tympanic membrane was injected, and on 25.11.36 bilateral myringotomy was performed and pus released from both ears. On 30.11 .36 weight-loss began, the left ear was discharging profusely, and the right tympanic membrane was red and slightly swollen. On 5.12.36 considerable weight had been lost and the child looked toxic and restless. Bilateral myringotomy was again performed, drainage being unsatisfactory from the left ear, and pus was released. On 8.12.36 further loss of weight occurred and temperature rose to $103^{\circ} \mathrm{F}$. On 9.12 .36 left myringotomy 
wound was re-opened and pus obtained, right myringotomy was repeated, but no pus found. On 10.12.36 temperature was normal but stools were loose, the child was very toxic and further weight loss occurred. There was slight discharge from the right ear. Until 14.12.36 the child remained very ill and left myringotomy was repeated, but no pus obtained. On 21.12.36 the child was gaining weight steadily, taking feeds well and its tympanic membranes were only slightly injected. This satisfactory state of affairs continued until 8.1.37 when the parents took the child home on their own responsibility although it was not quite ready for discharge from hospital.

\section{INVESTIGATIONS.}

Swabs : Nose-M. catarrhalis, diphtheroids and pneumococci.

Throat-negative.

Right ear-; Staph. aureus.

Urine : negative.

Faeces : negative.

Blood culture : negative.

Mantoux reaction : negative.

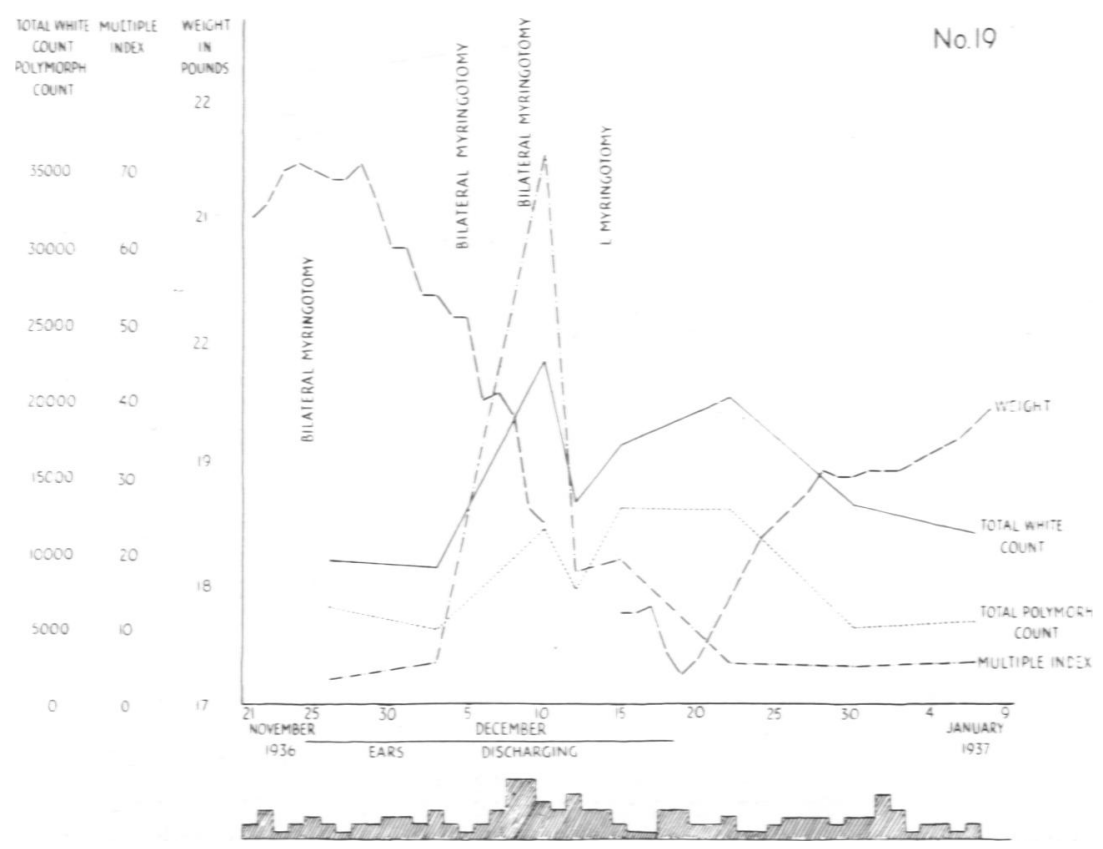

Fig. 4.- This graph shows slight rise of multiple index at second estimation. Then it rises very rapidly with the correspondingly marked loss of weight. At this point the weight and multiple index curves converge-indicating bad prognosis. Only after the third myringotomy when infection was overcome, does the multiple index curve fall. Simultaneously with its fall the weight curve begins to rise (giving divergence of the two curves), indicating a good prognosis. The multiple index was not normal when the child was taken out by its parents. The multiple index throughout gave a much more accurate estimation of the child's condition than the total white count or total polymorphonuclear count. 
Case 5.

A. C., male, aged 9 weeks, was admitted on 5.11.36, and died on 1.12.36.

History. There had been right otorrhoea for one week and left otorrhoea for one day before admission. Stools had been loose and offensive for one week, gain in weight unsatisfactory and feeds not taken well.

Condition on eXAmination. He was a small, thin baby, not dehydrated, with normal tension of the anterior fontanelle. There was purulent discharge from both ears. Other examination was negative and temperature not elevated.

Progress. For the next fortnight slow gain in weight occurred and both ears continued to discharge profusely. On 19.11.36 there was a rise of temperature to $99.9^{\circ} \mathrm{F}$. accompanied by marked loss of weight, the discharge from the ears having ceased. Bilateral myringotomy was performed and thick pus liberated from the left ear. Five days later discharge had again ceased and weight was stationary. Bilateral myringotomy was performed and again pus was obtained from the left ear. There was mild pyrexia $-99 \cdot 2^{\circ}-99^{\circ} \mathrm{F}$. On

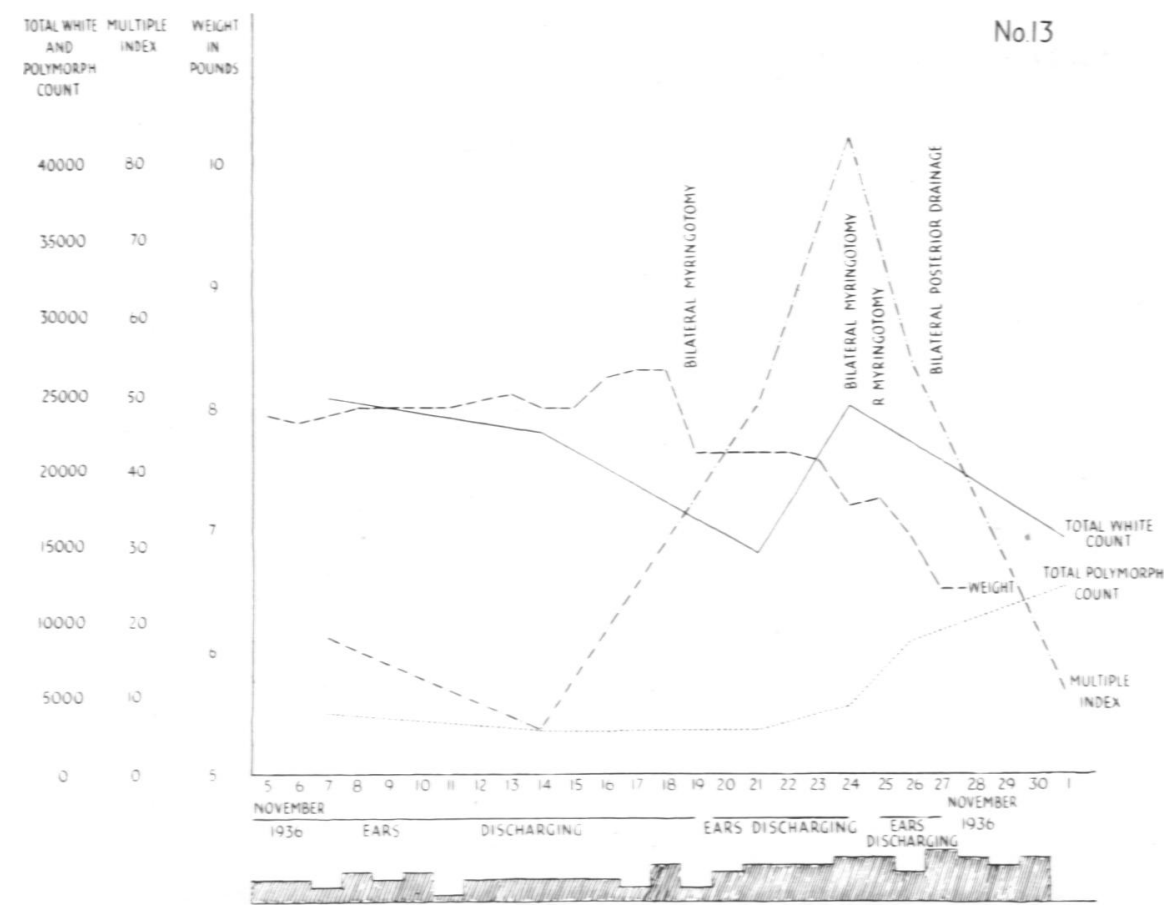

Fig. 5.-After admission the total white count was raised with poor neutrophilic response and the multiple index was raised. All three had fallen at the second estimation and the infant had gained in weight slightly. At the third estimation the multiple index had risen considerably while the total white count had fallen, thus giving an earlier and more accurate prognosis. After the myringotomies when the ears were discharging again, the multiple index fell somewhat. The last terminal fall of multiple index is probably due to marrow failure. The weight curve and multiple index curves converge, indicating a bad prognosis.

the following day right myringotomy was performed and slight amount of pus obtained. The infant's condition remained unsatisfactory and on 27.11.36 bilateral posterior drainage was performed and pus found in both mastoid cells. The child unfortunately died the following day. 
INVESTIGATIONS.

Swabs : Nose-M. catarrhalis, pneumococci.

Throat-M. catarrhalis, Staph. and pneumococci.

Right ear-Staph. aureus.

Urine : negative.

Left ear-C. diphtheriae.

Faeces : B. Morgan I.

Blood culture : negative.

Mantoux reaction : negative.

POST-MORTEM. The right mastoid antrum was well drained at operation, but on the left side the bone was unhealthy and the antrum contained pus. The large intestine was distended and slightly injected, the kidneys were pale and toxic and the right lung showed some basal congestion. Other examination was negative.

\section{Case 6.} 5.5.37.

B. S., male, aged 8 months, was admitted on 6.4 .37 , and discharged on

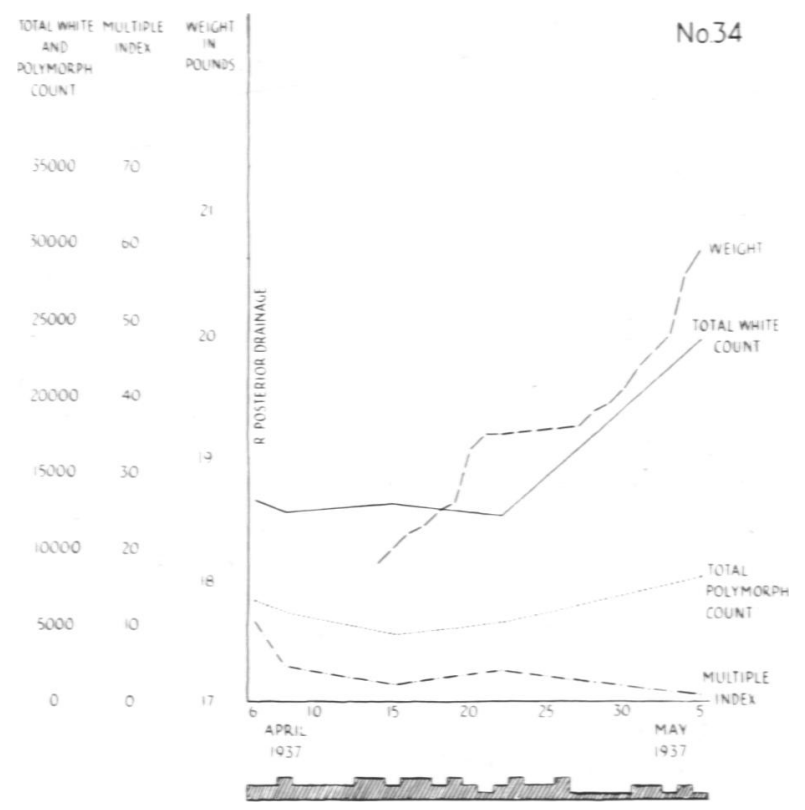

Fig. 6.-This child's general condition was very good and the multiple index, not markedly elevated, fell after the operation. The multiple index rose slightly on 22.4 .37 with the abscesses on the scalp and fell gradually to normal. Gain in weight was progressive. The total white count was not raised at first but had actually risen at the end. The child was nevertheless discharged and there were no untoward developments. The multiple index here was an accurate guide to the clinical state and the curve illustrates the comparatively mild disturbance which occurs in cases of classical mastoiditis which is in accord with the clinical state of this infant.

History. For one week there had been a tender swelling behind the right ear which the infant would not allow its mother to touch.

Condition on EXAMINATION. This was a well-nourished infant with swelling, redness and tenderness over the right mastoid process. The right 
tympanic membrane was injected and bulging posteriorly. The left tympanic membrane was slightly injected. Other examination was negative and temperature was $99^{\circ} \mathrm{F}$.

Progress. On the evening of admission right posterior drainage was performed and pus found sub-periosteally. The bone was necrotic. Four days later condition was satisfactory. Gain in weight began and discharge lessened. On 23.4.37, when the child was almost fit for discharge, temperature rose to $100 \cdot 2^{\circ} \mathrm{F}$. and several small abscesses occurred on scalp These recovered satisfactorily and the infant was discharged well on 5.5.37.

INVESTIGATIONS.

Swabs : Nose-Staph., strep. and diphtheroids.

Throat-Pneumococci II.

Operation-Staph. albus.

Urine : faint trace of albumin.

Faeces : negative.

Blood culture : negative.

Mantoux reaction : negative.

Case 7.

A. L., female, aged 9 weeks, was admitted on 29.4.37, and died on 16.5.37.

HisTORY. This child had had right otorrhoea for two weeks. Three days before admission a swelling developed behind the right ear and then the left ear commenced to discharge. Some vomiting had occurred but no diarrhoea and gain in weight had been satisfactory.

Condition on examination. This was a fretful child in fair condition. There was redness, tenderness and swelling over the right mastoid process. The right tympanic membrane was acutely inflamed and there was profuse thick discharge. The left tympanic membrane was also reddened posteriorly and there was profuse discharge. Temperature was not elevated.

Progress. Right posterior drainage was performed and pus was found subperiosteally. Operation on the left ear was contemplated but unfortunately not performed. Temperature rose after operation to $99.6^{\circ} \mathrm{F}$. but rapidly subsided. On 8.5.37 the child's condition was very satisfactory but the left ear was discharging profusely. On 12.5.37 the child looked ill, the temperature rose to $101 \cdot 2^{\circ} \mathrm{F}$. and stools became loose. Left otorrhoea ceased on 12.5.37 and left myringotomy was without result. This pyrexia continued until the end and the child became very ill and toxic. The infant ultimately died on 16.5.37.

INVESTIGATIONS.

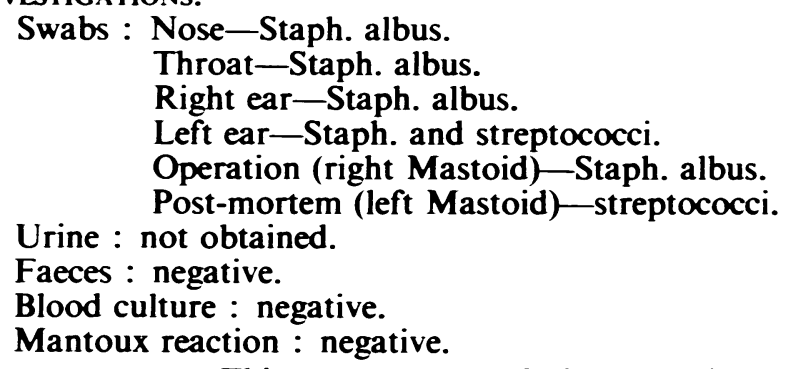

Post-MORTEM. This was a case of right classical mastoiditis and unfortunately only a partial post-mortem was allowed. The right mastoid antrum was satisfactorily drained at operation. On the left side there was no external evidence of mastoiditis but when an incision was made over the mastoid process a commencing subperiosteal abscess was discovered with a sinus, through 
which a probe could be put, leading into the mastoid antrum which was full of pus. There was also pus in the left middle ear. Examination of the rest of the body was not permitted.

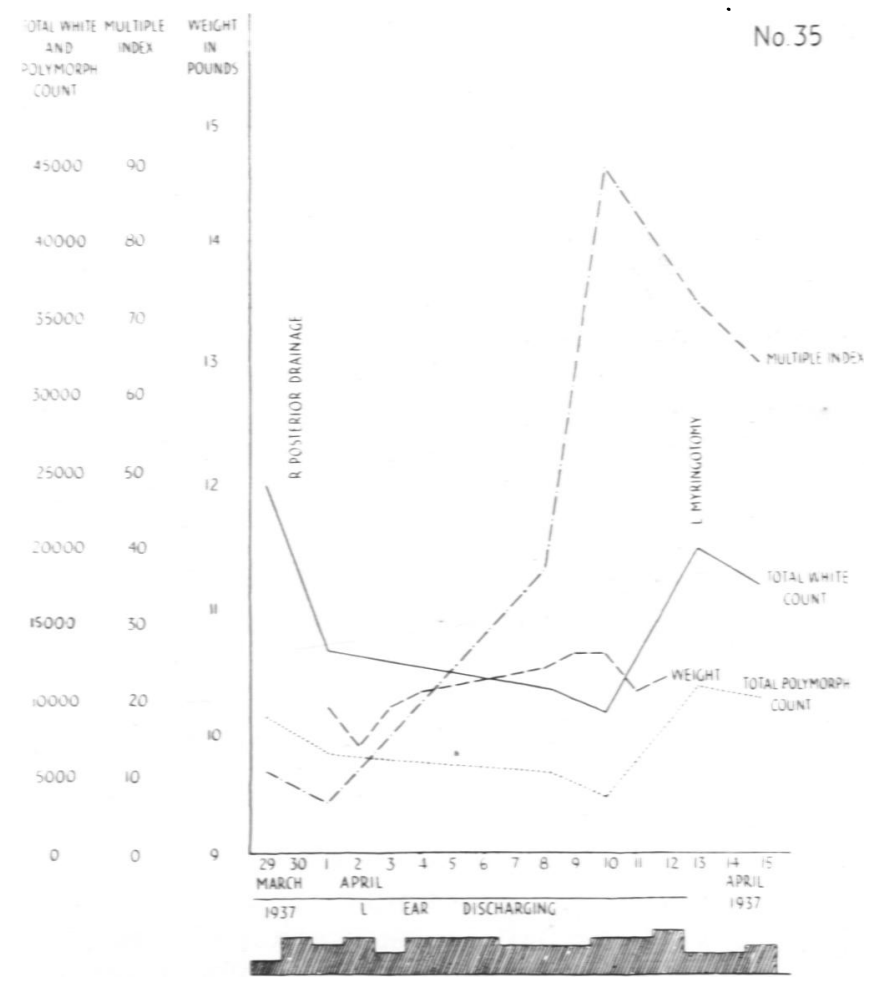

Fig. 7.-The multiple index was elevated but not markedly so on admission and fell after the operation. On 8.5.37 the multiple index had risen sharply and continued to do so until 10.5.37, during which time the child's condition appeared satisfactory. On 12.5.37 the infant became very ill, i.e. the rise in the multiple index preceded the onset of the acute illness by at least a week. The total white count gave no indication of this occurrence. It is also probable that it was the infant's left mastoid which caused its death, and that if it had also been operated on the fatal issue might have been averted. The fall in the multiple index towards the end was probably due to marrow failure. The multiple index throughout this case gave a clear index of prognosis and the progress of this infant's illness.

\section{Discussion}

In an attempt to analyse the many blood counts performed, the cases were divided into the following clinical groups :-

A. Mild cases without toxicity or dehydration, e.g. cases 1 and 2.

B. Cases, toxic on admission, and proved either at operation or postmortem to have latent mastoiditis.

C. Cases, toxic on admission, with otitis media but never shown to have latent mastoiditis.

D. Cases which became toxic in hospital, proved to have latent mastoiditis (maximum readings at height of toxicity), e.g. cases 3, 5 and 7.

E. Cases which became toxic in hospital, with otitis media only (maximum readings at height of toxicity); e.g. case 6 . 
F. Cases presenting the classical picture of mastoiditis, e.g. cases 6 and 7 .

Averages have been calculated of the first three estimations made in groups $A, B, C$ and $F$. In groups $D$ and $E$ the average of the reading taken at the height of the toxicity has been calculated. These averages are recorded in the following tables :-

\begin{tabular}{|c|c|c|c|c|c|c|c|c|c|}
\hline \multirow[b]{2}{*}{ GROLP } & \multicolumn{3}{|c|}{ FIRST ESTIMATION } & \multicolumn{3}{|c|}{ SECOND ESTIMATION } & \multicolumn{3}{|c|}{ THIRD ESTIMATION } \\
\hline & $\begin{array}{l}\text { TOTAL } \\
\text { WHITE } \\
\text { COUNT }\end{array}$ & $\begin{array}{l}\text { TOTAL } \\
\text { POLY- } \\
\text { MORPH. } \\
\text { COUNT }\end{array}$ & $\begin{array}{l}\text { MUL- } \\
\text { TIPLE } \\
\text { INDEX }\end{array}$ & $\begin{array}{l}\text { TOTAL } \\
\text { WHITE } \\
\text { COUNT }\end{array}$ & $\begin{array}{l}\text { TOTAL } \\
\text { POLY- } \\
\text { MORPH. } \\
\text { COUNT }\end{array}$ & $\begin{array}{l}\text { MUL- } \\
\text { TIPLE } \\
\text { INDEX }\end{array}$ & $\begin{array}{l}\text { TOTAL } \\
\text { WHITE } \\
\text { COUNT }\end{array}$ & $\begin{array}{l}\text { TOTAL } \\
\text { POLY- } \\
\text { MORPH. } \\
\text { COUNT }\end{array}$ & $\begin{array}{l}\text { MUL- } \\
\text { TIPLE } \\
\text { INDEX }\end{array}$ \\
\hline $\begin{array}{l}\mathbf{A} \\
\mathbf{B} \\
\mathbf{C} \\
\mathbf{F}\end{array}$ & $\begin{array}{l}14,700 \\
19,400 \\
17,200 \\
22,000\end{array}$ & $\begin{array}{c}5156 \\
8297 \\
6997 \\
10,220\end{array}$ & $\begin{array}{r}11 \cdot 5 \\
45 \cdot 5 \\
21 \cdot 1 \\
6 \cdot 5\end{array}$ & $\begin{array}{l}14,200 \\
19,300 \\
17,400 \\
16,600\end{array}$ & $\begin{array}{c}4847 \\
10,652 \\
8727 \\
7029\end{array}$ & $\begin{array}{r}14 \cdot 4 \\
28 \cdot 3 \\
12 \cdot 8 \\
4 \cdot 0\end{array}$ & $\begin{array}{l}14,400 \\
26,400 \\
19,300 \\
15,200\end{array}$ & $\begin{array}{c}5685 \\
16,161 \\
11,703 \\
6274\end{array}$ & $\begin{array}{r}7 \cdot 3 \\
26 \cdot 2 \\
6 \cdot 1 \\
2 \cdot 2\end{array}$ \\
\hline
\end{tabular}

\begin{tabular}{|c|c|c|c|c|}
\hline & \multirow{2}{*}{ GROL'P } & \multicolumn{3}{|c|}{ MAXIMLM READING AT HEIGHT OF TOXICITY } \\
\hline & & $\begin{array}{l}\text { TOTAL } \\
\text { WHITE } \\
\text { COLNT }\end{array}$ & $\begin{array}{c}\text { TOTAL } \\
\text { POLYMORPH. } \\
\text { COUNT }\end{array}$ & $\begin{array}{l}\text { MLLTIPLE } \\
\text { INDEX }\end{array}$ \\
\hline$\underset{E}{\mathrm{D}}$ & $\begin{array}{l}\ldots \\
\ldots\end{array}$ & $\begin{array}{l}17,100 \\
15,800\end{array}$ & $\begin{array}{l}5890 \\
8515\end{array}$ & $\begin{array}{l}47 \cdot 4 \\
38 \cdot 9\end{array}$ \\
\hline
\end{tabular}

These tables show that in group A (mild cases) the average total white count remains about the level of a high normal with a not unduly raised multiple index which falls. In the other groups the average total white counts are elevated but not in such a way as to be of diagnostic help. In group B (toxic cases of proved mastoiditis) the average multiple index is about four times as high as in the mild cases and shows a sustained elevation, while in group C (toxic cases of otitis media only) the average multiple index is about twice as high as in mild cases and shows gradual improvement. The cases which became toxic while in hospital show a high average multiple index at the height of the toxicity, those with otitis media only being slightly lower than those with mastoiditis. The cases of classical mastoiditis (group F) show an average multiple index about half that in the mild cases with gradual improvement. While a close scrutiny of the tables from which the average figures given were calculated would reveal exceptions to these averages, it is suggested that the height of the multiple' index may be of some diagnostic significance, taken, as it always must be, in conjunction with the clinical findings and the clinical condition of the child. The height of the multiple index is of no value in selecting an optimum time to operate as degree of response varies from infant to infant. For instance, in case 2 several small scalp abscesses caused a rise of multiple index to $4 \cdot 0$, while in another case, not described in this paper, bilateral styes caused a rise to 89.6. In another case the infant suffered from acute non- 
perforative otitis media and was never severely ill, but its multiple index was as high as $\mathbf{7 5 \cdot 2}$. The value of the multiple index in prognosis can be seen from the accompanying graphs.

\section{Conclusions}

(1) Ordinary white counts and differential counts are of no value in prognosis or differential diagnosis.

(2) Analysis of the polymorphonuclear cells, on the lines suggested by Schilling and others, is applicable to infants of this age group.

(3) The use of some index of ' left shift' such as the multiple index employed in the present series, is possibly of diagnostic value and certainly of prognostic value.

(4) Single counts are not nearly so useful as a series of estimations.

(5) The height of the multiple index is of no value as an indication of when to operate, for each infant's response to its infection varies and such counts must always be considered in conjunction with the clinical condition.

(6) An infant's weight has long been regarded as a good indication of its progress, and the manner in which the multiple index rises with loss of weight and falls with gain in weight is quite striking. As the multiple index and kindred indices are established as reliable indices of infection somewhere in the body, and as the multiple index in the present series fell and rose according to the success or non-success of treatment directed against the aural infection, it seems reasonable to conclude that the aural infection was the immediate cause of the infant's illness.

Thanks are due to Dr. W. E. Crosbie, Medical Superintendent, Alder Hey Children's Hospital, for permission to publish this work, and to Dr. N. B. Capon for his advice and criticism.

\section{REFERENCES}

Alden, A. M., and Demotte, J. A. (1931). Ann. Otol., St. Louis, 40, 95

Arneth, J. (1904). Disch. med. Wschr., 30, 54.

Boies, L. R. (1931). Arch. Otolaryng., Chicago, 13, 159.

Crocker, W. J., and Valentine, E. H. (1934). J. Lab. clin. Med., 20, 172.

Darling, J. F. (1908). Edinb. med. J., 25, 125.

Dench, E. B. (1908). Laryngoscope, St. Louis, 18, 958.

Fletcher, E. G., and Mitchell, A. G. (1927). Amer. J. Dis. Child., 34, 807.

Gale, C. K. (1928). Laryngoscope, St. Louis, 38, 538.

Japha, A. (1900). Jhrb. Kinderheilk, 52, 242.

Klenerman, P. (1934). Arch. Dis. Childh., 6, 343.

Martin, A. T., and Ellenberg, S. J. (1935). Arch. Pediat., 41, 285.

McConkey, G., and Couper, E. C. R. (1938). Arch. Dis. Childh., 13, 137.

Mitchell, A. G. (1915). Amer. J. Dis. Child., 9, 358.

Ockel, G. (1924). Arch. Kinderheilk., 75, 40.

Rogatz, J. L. (1930). Amer. J. Dis. Child., 6, 70.

Rosenwasser, H., and Rosenthal, N. (1931). Arch. Otolarıng., Chicago, 14, 291.

Sabin, F. R., Cunningham, R. S., Doan, C. A., and Kindwall, J. A. (1925). Johns Hopk. Hosp. Bull., 37, 14.

Schilling, V. (1929). The blood picture and its clinical significance. Trans. by R. B. H. Gradwohl, London.

Schüssler, E. (1924). Jhrb. Kinderheilk., 104, 87.

Washburn, A. H. (1934). Amer. J. Dis. Child., 47, 993.

- (1935). Ibid., 50, 395, 413.

Weiss, A. (1931). Arch. Otolaryng., Chicago, 13, 647. 